\title{
15 Publics-in-the-Making: Crafting Issues in a Mobile Sewing Circle
}

\author{
Kristina Lindström and Åsa Ståhl
}

In this chapter we will explore the potentialities of publics-in-the-making-that is, publics that come out of making things together and that are continuously reconfigured by their participants, human and nonhuman. The potentialities of such public engagement will be explored through Threads-a Mobile Sewing Circle, a traveling exhibition in which people are invited to embroider a message received by means of SMS, either by hand or with an embroidery machine connected to a mobile phone with bespoke software. This is an invitation to stitch together different kinds of technologies, temporalities, materialities, practices, and participants. What makes participants gather in Threads is not that they necessarily know each other since before, neither that they necessarily have a shared problem that they want to address. What they do share is that they have responded to an invitation that, we argue, articulates an area of curiosity-ways of living with technologies - rather than a predefined problem. Our concern in this chapter is the co-articulations that result from a particular way of gathering and from particular ways of engaging with everyday technologies.

\section{Threads_a Mobile Sewing Circle}

The photo reproduced here as figure 15.1 shows some people gathered around a table. Some are engaged in handicraft. Others are talking. Overall they look pretty happy. If you look a bit closer you can see that someone has embroidered on the tablecloth. In the background there are more embroideries hanging on clotheslines. If you look even closer you can see that the man standing near the center of the photo is holding a mobile phone in his hand.

Threads has been traveling to public spaces, such as rural community centers and libraries, in Sweden. It doesn't have a set number of participants. To make its travels possible, substantial work has been put into making Threads more mobile by the two of us (Lindström and Ståhl, the initiators of the project) and by five partners: Swedish Traveling Exhibitions, Vi Unga (a youth-led organization for leadership, democracy, and entrepreneurship), the National Federation of Rural Community Centers, 


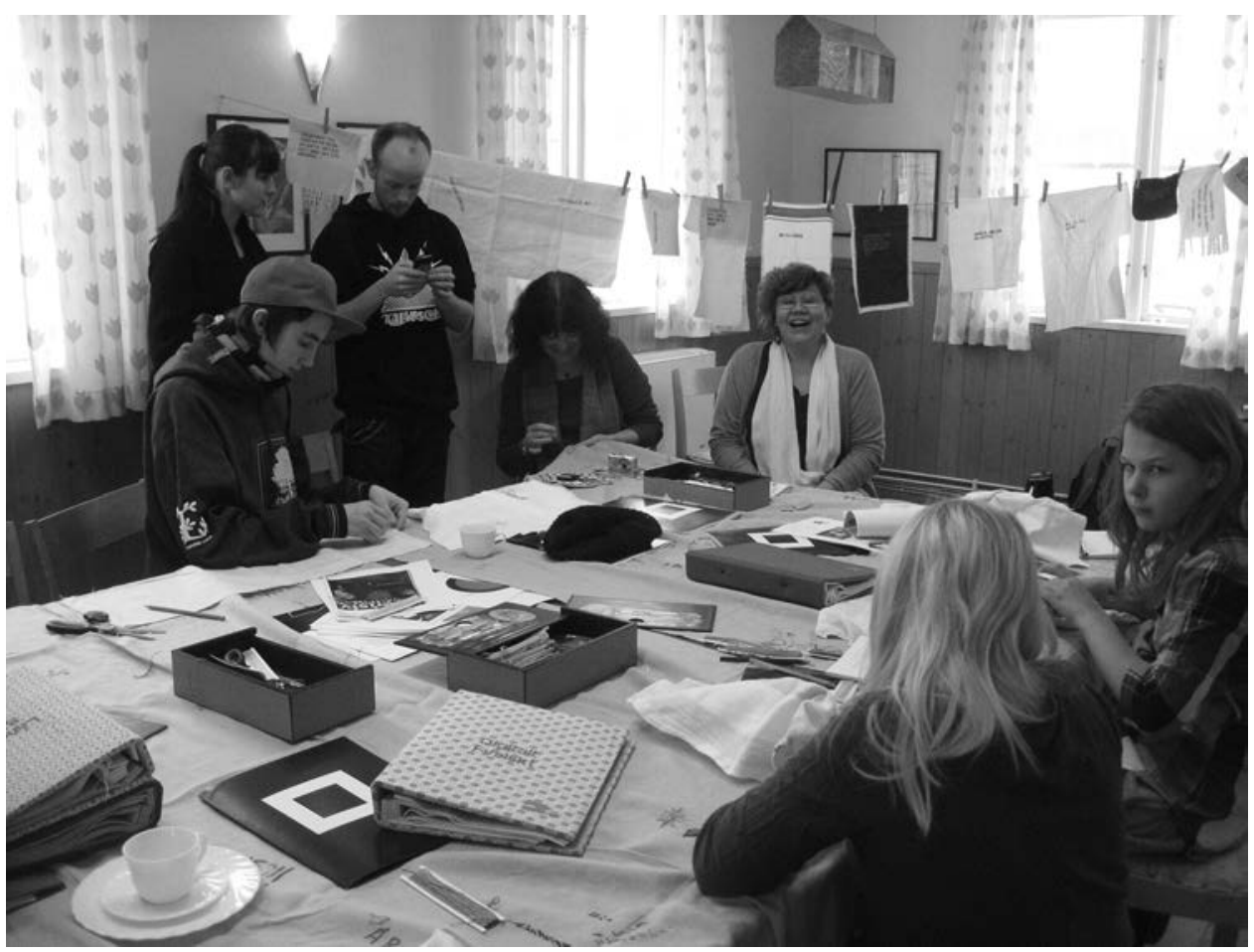

Figure 15.1

An educational sewing circle in Åsgarn in 2011. Åsa Ståhl (CC:BY-NC).

Studieförbundet Vuxenskolan (a national organization that arranges study circles), and Malmö University. Together we worked to set up an emerging network that enabled Threads to travel around Sweden between 2010 and 2013.

The two of us hosted educational sewing circles during which we handed over some responsibilities to local hosts, who would then take Threads to their rural community center. The educational sewing circles lasted about six hours, and were based on learning by doing. The hosts were paid a small sum of money for their work by one of the partners.

All of the things that traveled with Threads fit into two cases that could be carried in the trunk of a car. Within a region, they were usually are transported between rural community centers by the local hosts. Transportation of the cases between regions was arranged and paid for by one of the partners. The schedule of the tour was announced on a website. There was only one set of equipment, so the sewing circles were consecutive.

Joint efforts and resources among the partners were also put into facilitating and supporting this emerging network. Each partner has had at least one paid representative who has worked part-time with the project and has contributed with resources and 


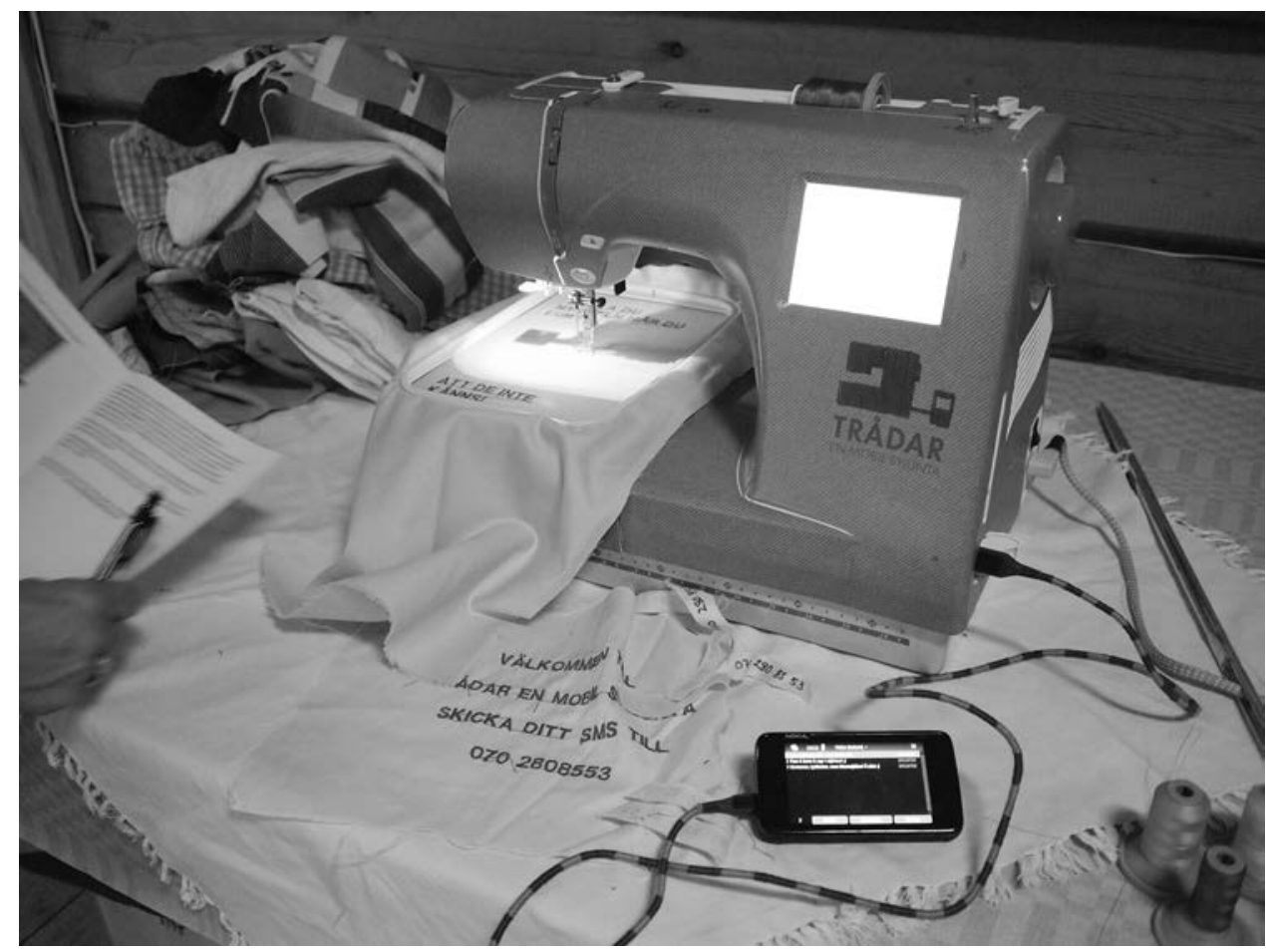

Figure 15.2

The invitation to Threads was to embroider messages received by means of SMS either by hand or with an embroidery machine connected to a specially programmed mobile phone. Kristina Lindström (CC:BY-NC).

facilities, such as local contacts and a place to host Threads. The two of us did this as part of our PhD studies, funded by public means.

About ninety sewing circles have been hosted. Some of the embroidered messages are now in a museum for cultural heritage, ${ }^{1}$ and the Ministry of Culture has used the project as an example of collaboration between cultural institutions and civil society. ${ }^{2}$

The partners have various motivations for engaging with Threads. For example, one of the reasons for Swedish Traveling Exhibitions to join was that they wanted to explore how to design more participation-oriented exhibitions. The National Federation for Rural Community Centers wanted to reactivate rural community centers as meeting places. Studieförbundet Vuxenskolan was, among other things, interested in considering what a study circle could be. Although all the collaborating organizations had slightly varied main interests, they all shared an interest in participation and engaging the public. This interest made us set up Threads, where we invite the public 


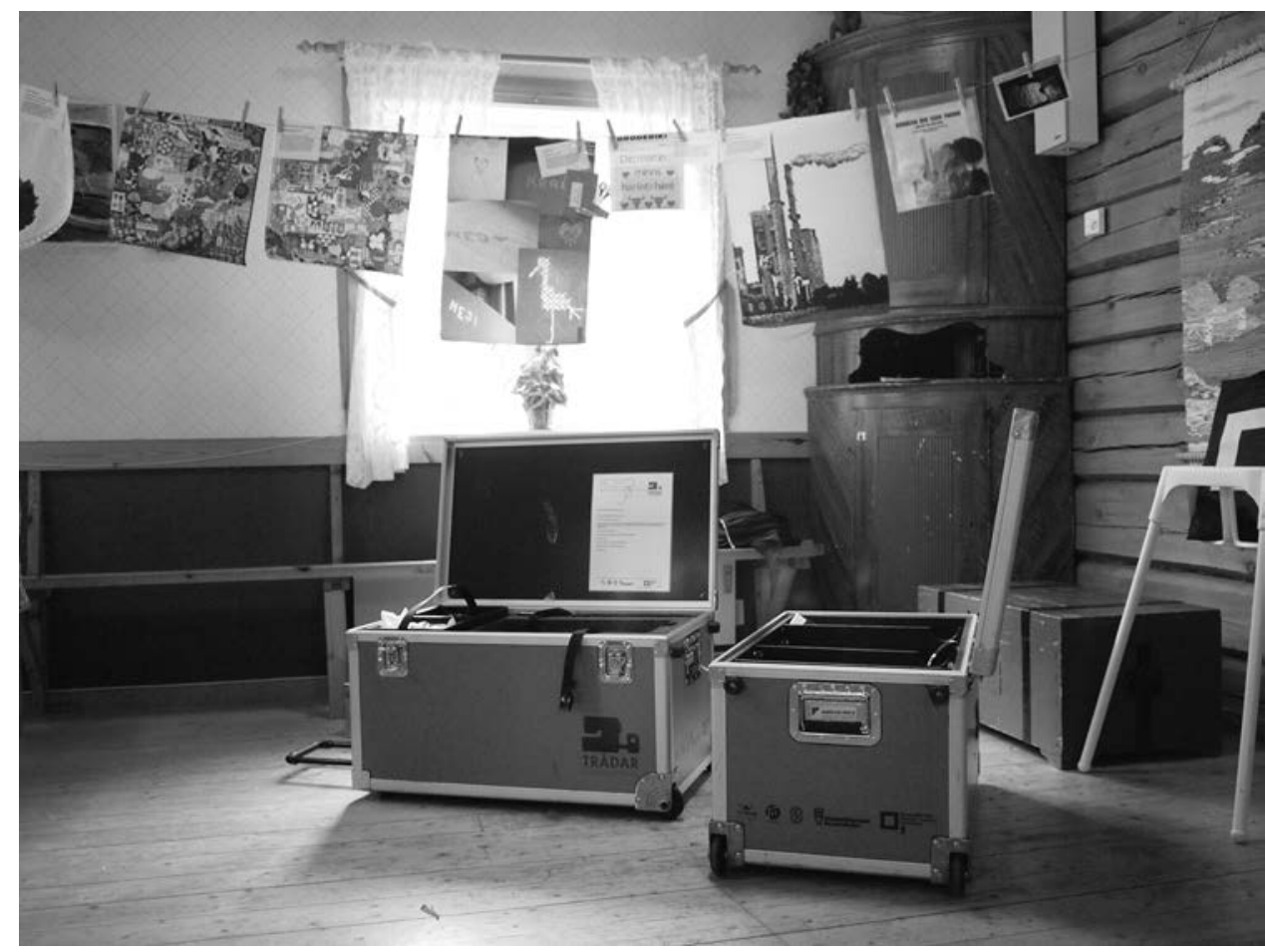

Figure 15.3

The two blue cases. Kristina Lindström (CC:BY-NC).

to engage with issues of living with technologies, new and old, digital and physical, through making things together.

\section{Toward Publics-in-the-Making}

Usually a sewing circle has a set number of participants who meet regularly in a domestic setting. Participants in Threads have likened sewing circles to other groups that gather to make or do things together: hunters, feather pickers, people who share a garage, and so on. To this list could also be added makerspaces and hackerspaces, which signal urban settings rather than rural ones. The reason for these groups or collectives to gather to make things differ. In some cases it might be because it is more fun to do things together. There might also be parts of the making, for example when repairing a car, that are difficult to do by oneself. The need for collective efforts might stem from a necessity of sharing knowledge, or joint investments in expensive equipment. As a consequence of the different kinds of makings, the conditions for socializing, talking, 
and so on also differ. The kind of belonging that is generated might also differ. Some are closed communities where the participants might know each other very well through sustained patterns of gathering; others are occasional get-togethers with less strong ties.

Waldén (2002) has helped us to understand sewing circles, as well as other groups that gather to make things, as sites of practicing democracy and creating publics. She has described sewing circles as hidden female publics, or shadow governments. In her description, handicraft is sometimes characterized as an excuse for women to gather in order to discuss matters important to them, something that was otherwise difficult for them to do. An important characteristic of these groups is, according to Waldén, that they were closed groups in which trust was built up over time. While the participants did not have access to formal decision-making forums, the sewing circles enabled them to make informed but informal decisions, which in some cases could be brought further to forums in which the matters were addressed formally.

We very much appreciate Waldén's work, but we are more interested in considering the potentialities of making things together as a kind of public engagement as something in itself, not necessarily an alibi for something more important, to talk. In other words, we want to explore how making, tinkering, and direct engagement with technologies and materialities can also become a way of understanding, negotiating, or imagining issues of living with technologies.

Marres $(2005,2012)$ uses the American pragmatism of John Dewey and Walter Lippmann, feminist technoscience, and Science and Technology Studies (STS) to argue for material participation as a specific mode of public engagement. The time of Dewey and Lippmann-the early twentieth century-was a time of technological development in communications, in transportation, and in the means of production. Much like today, technological development often resulted in complex issues that cannot easily be resolved by experts or institutions, but are left to the public to deal with. Although this can be seen as a threat to democracy, Dewey and Lippmann argued that this problematic entanglement, of being affected by an issue and not having a direct stake in the matter, is both the problem of the public and that which makes the public emerge. The constitution of a public is thereby characterized by being both inside and outside, which certainly is a problematic position. Marres fuses the positions of Lippmann and Dewey in this summary:

[T]he public's problem is that social actors are too involved in an issue to qualify as mere outsiders, who could leave the care for issues to other professionals. But at the same time they are too much of a stranger to the public affair in question to have access to the resources required to deal with them. (Marres 2012, 49-50)

In technological societies, where material entanglements continuously shift, it is not likely that these publics will map onto already existing groupings. Thereby these are rather unstable and ephemeral collectives that often lack a shared language, procedures, 
or locations. The kind of gatherings, or publics, described by Waldén, where the participants usually know each other well, thereby differ from Lippmann and Dewey's understanding of publics.

This position of being both inside and outside can be approached as a problem of representation, which for example is the case in liberal theory. Marres argues that it is more constructive to think of this simultaneous inside-and-outside position as a problem of relevance. This means that what an issue is, who is affected, and what procedures and institutions should be used to address it, is not a given. The challenge then becomes to articulate issues, actors, and their entanglements, or to establish relations of relevance. In line with Dewey and Lippmann, Marres points out that it should not be expected of a public to solve the issue that is in-the-making. The problem of relevance is a distributed problem, for the public, institutions, and others to care for. This is not simply done through talk or debate in political forums, but also through everyday practices such as when to turn on a washing machine or turn down the temperature in the house, what Marres (2012) describes as "material participation." What characterizes this participation is that material entanglements in issues and public engagement cannot be separated. In other words, Marres argues that use, and other ways of living with technologies, are potentially modes of participation in public affairs. This argument also implies that we cannot simply position the political in certain spheres, separated from the private or activities such as making or doing. It also invites us to think of the everyday as an environment for participation.

We align with Marres' argument that we become materially entangled, and possibly implicated in a range of issues, through mundane usage of technologies. What these issues are and who might be implicated in them is, however, not a given. Through the concept of publics-in-the-making, we want to explore and propose making as a means for co-articulations of issues. This means to acknowledge that issues are not just there, but always in-the-making as a joint effort between those humans and nonhumans who have the capacity to act in the given situation.

The focus on co-articulations through making also implies a critique against a separation between thinking and making as well as between public and private, which has been a dominant dichotomy in Western society. Similar thoughts can be found in works by Sennett (2008), Gauntlett (2011), and Ratto (2011a,b). Gauntlett (2011) argues for making as a mode of connecting ideas to other people and to our environment. With support from Ruskin and Morris, two main thinkers in the Arts and Crafts movement in Victorian England, Gauntlett argues for everyday creativity, that makes people happy. This should be understood in comparison to industrialization, which divided production into discrete tasks, and thereby also separated making from thinking.

Sennett (2008) also argues against the separation between thinking and making, but from an ethical position. He conceptualizes making, or craft, partly from the perspective of curiosity for what is possible to make and craft, and how to do it well. This 
curiosity is, however, not innocent. He means that we cannot allow the curiosity to run astray and judge in hindsight whether the outcome was beneficial or not. Without ethical considerations, curiosity might allow for the development of devastating innovations such as the atom bomb (ibid.). Instead of leaving the ethical question to the public, that only practices an after-the-fact ethics by responding to pressing issues, Sennett argues that we need to develop a craftsmanship that continuously asks ethical questions, in-the-making. This is a temporal and spatial shift which requires involvement rather than privileging distanced observers or representatives who can come and make a judgment afterwards. Curiosity, in Sennett's conceptualization, is then about the new, about what is possible to make, and must always be engaged with through ethical questions.

Ratto (2011a) works in more academic settings with making, in what he calls "critical making labs." In line with Sennett and Gauntlett, Ratto also aims to challenge the long tradition within Western society of separating thinking and making through highlighting "the interwoven material and conceptual work that making involves" (Ratto 2011b, 204). The reason for doing this is that Ratto and his colleagues have experienced that there is a gap between our "conceptual understandings of technological objects and our material experiences with them" (Ratto 2011a, 253). Critical making is an exploration of how people can critically connect society and technology with their own daily experiences, through investing in making physical creations and conceptual explorations. To do so, Ratto argues that the combination of making and social theorizing is preferred to external viewing: “... the ability of the participants to engage with the social theories presented to them and to develop and share new understandings was intimately related to the joint conceptual and materially productive work" (ibid., 258). As a potential of critical making, Ratto puts forward that investments made by those who participate in critical making can engender a caring for sociotechnical systems. We understand this as taking responsibility for the applied work, which might involve innovative technological or conceptual making, that one has created.

Marres' version of American pragmatism, combined with feminist technoscience and STS coupled up with Sennett, Gauntlett, and Ratto, leads us, instead of simply treating craft as an alibi for gathering, to consider the potentialities of making in terms of its gathering potential, and as a mode of engaging with our material entanglements. This is a move toward acknowledging co-constitution of humans and nonhumans, sometimes labeled the material turn (see, for example, Åsberg and Lykke 2010; Christensen and Hauge 2012; Hird and Roberts 2011), and a move away from the dominant discursivity, which has predominantly regarded the problem of the public as a lack or a deficit.

To explore the concept of publics-in-the-making further we will attend to Threads, and see how issues are articulated and made relevant through the making in Threads. But first we will take a closer look at the invitation, one of those things which makes people gather. 


\section{Invitation}

Compared to a public that comes together because of being implicated in the same issue, or because of belonging to the same collective, Threads is related to, but differs from, both, in that it gathers as a response to a somewhat public invitation. The invitation is made through various means, for example through posters and flyers, using formal and informal networks of the collaborating organizations, through the project's website, and on a few occasions there have been ads in the local newspapers. Compared to the kind of sewing circles that Waldén has studied, Threads does not consist only of close friends, but of people who have responded to an invitation without necessarily knowing each other.

The invitation, in short, is to embroider a message received by means of SMS in a sewing circle, either by hand or with a machine, during one day. Without trying to make any scientific claims as to what motivates participants to join, it feels safe to say that there are multiple reasons for responding to the invitation. Several participants have expressed that they did not quite understand what Threads was or could be, but that the invitation made them curious. One woman said that for her, to come to Threads was a leap of faith. Another woman said that she was happy not to know too much because that puts pressure on her to prepare herself and perform. Others are very eager to prepare and bring, for example, embroideries or other handicraft.

It is also worth mentioning that the invitation doesn't only take place in advance, before the gathering, but continues throughout the day, through ours and other hosts' introduction of the day, through the setting in the room, through embroidered flyers with instruction about how to forward a message to the machine, and much more. In other words, invitations are made through talk and text as well as through material configurations.

Keshavarz and Mazé (2013) argue that through framing a design project, for example through the articulation of an invitation, a problem or issue is defined. To some extent this means that initiators of any kind of participatory project, more or less, in advance prevent the possibility for dissensus. One way of understanding this argument is that an invitation and who it is directed to, frames what the problem is, how to engage with it, and who are to be concerned. We certainly agree with Keshavarz and Mazé, that making invitations is a way of framing-and doing so is not innocent.

However, rather than refraining from making invitations or articulations, we want to explore the potentiality in making invitations that are more about articulating an area of curiosity, as opposed to defining a problem. The particular technologies and materials that are part of the invitation to Threads have normative capacities, but these are ambivalent (see more in Marres 2012). This means that we do not presuppose what might be an issue and whom it might concern. As we have mentioned, publics-in-themaking gather although we do not quite know the issue. However, the invitation to embroider a message received by means of SMS, which is articulated using a variety of 
means, in different locations and times, is, as we see it, a way of expressing an area of curiosity as well as a proposal about how to engage with it. The particular area of curiosity in Threads can be framed as meetings of old, new, digital, and physical means of communication. And the way we engage with this in Threads is through direct engagement with the technologies that the participants are entangled and engaged with in everyday use.

\section{Co-articulations through Making in Threads}

In this section we will introduce some examples of how issues are co-articulated through the making in Threads. These are responses to the area of curiosity, which is proposed through the invitation. Our accounts are based on material collected in connection with the educational sewing circles hosted by the two of us. The material consists of our field notes as well as images taken by us as well as other participants.

Although there was an atmosphere of joy and happiness on a crisp winter day, as can be seen in figure 15.1, some members of that particular group also had difficulties aligning themselves with all the things and practices introduced in Threads. Some, for example, were troubled by the embroidery machine and the mobile phone.

During the introduction of all the various materials and technologies that are part of Threads, an image was taken to learn how to upload images to the website (see figure 15.4) as a form of self-documentation. In this situation of learning-by-doing, a sense of non-alignment, separation and split was expressed when the participants saw the picture. One of them said that we should write not only "nya värdar" but also "skilda världar" (a bit of wordplay). With or without the ' 1 ' in "världar," "skilda världar" is pronounced the same way. But depending on whether the ' 1 ' is there, it can be translated to mean either "separate worlds" or "separate hosts." We are not speculating on which of all the possible splits this caption is referring to, but we take it as an acknowledgment of simultaneously belonging and being separate. Threads gather participants that are not all acquainted with each other. We have put lots of what can be taken to be contradictions into the setup of Threads, such as an embroidery machine and hand embroidery, smart phones and rurality. We have also invited curiosity toward how these contradictions could possibly be stitched together, or held separate. However, that is a matter of negotiations between the human and nonhuman participants. In this case the human participants responded to the image with playful resistance toward being taken as a simple unity of "new hosts," as if they had shared issues and ways of engaging with our multifarious invitation. In a coarticulation between humans and nonhumans, a non-specified difference was articulated.

The ambiguous feelings toward the relation between the familiar and unfamiliar, and the old and new was expressed by one of the participants through embroidering a phrase in Swedish: "Svetten lackar redan" (see figure 15.5). It was embroidered with 


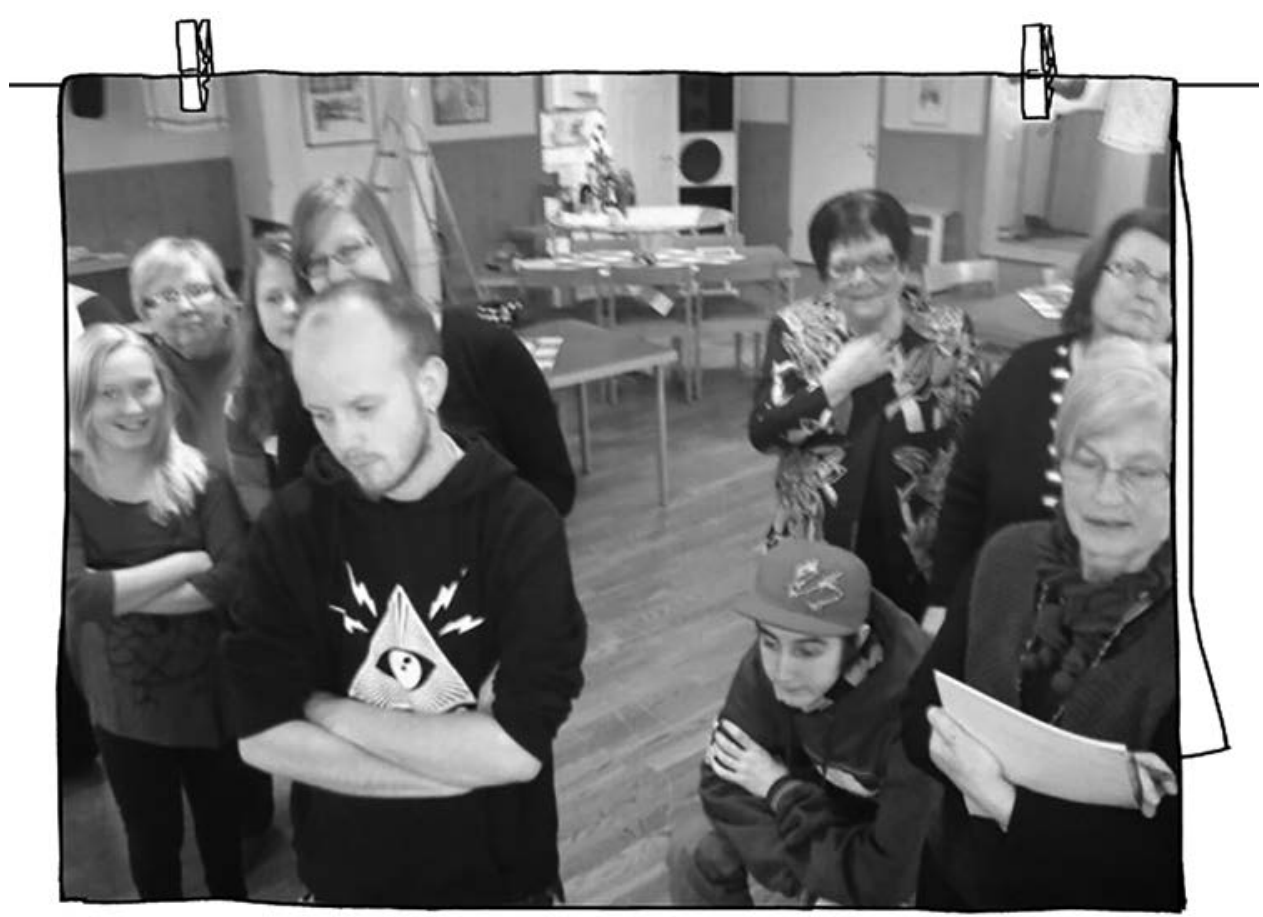

Nya värdar. Skilda världar?

Figure 15.4

"New hosts. Separate worlds?" Authors' translation to English of the caption for an image posted on www.mobilsyjunta.se during an educational sewing circle. Kristina Lindström and Åsa Ståhl (CC:BY-NC).

the machine on an apron that she had made by hand. The phrase cannot easily be translated but can be understood as both the anticipation of something coming up, and sweating because of hard work being done. She dealt with her anxiety toward the new technologies through actually using them in combination with something more familiar to her: a hand-woven apron. The making in this case was not only happy making but also rather demanding. First she had to ask for help to write and forward the text message to the embroidery machine. Then she had to go outside to send the message, since the reception at the rural community center was weak. In addition to these efforts, it is worth noticing that the making had actually begun even before that day, when she made the apron out of a linen towel. She was proud of having made the towel, but had put it in a hope chest and never used it until now. She did not follow the 


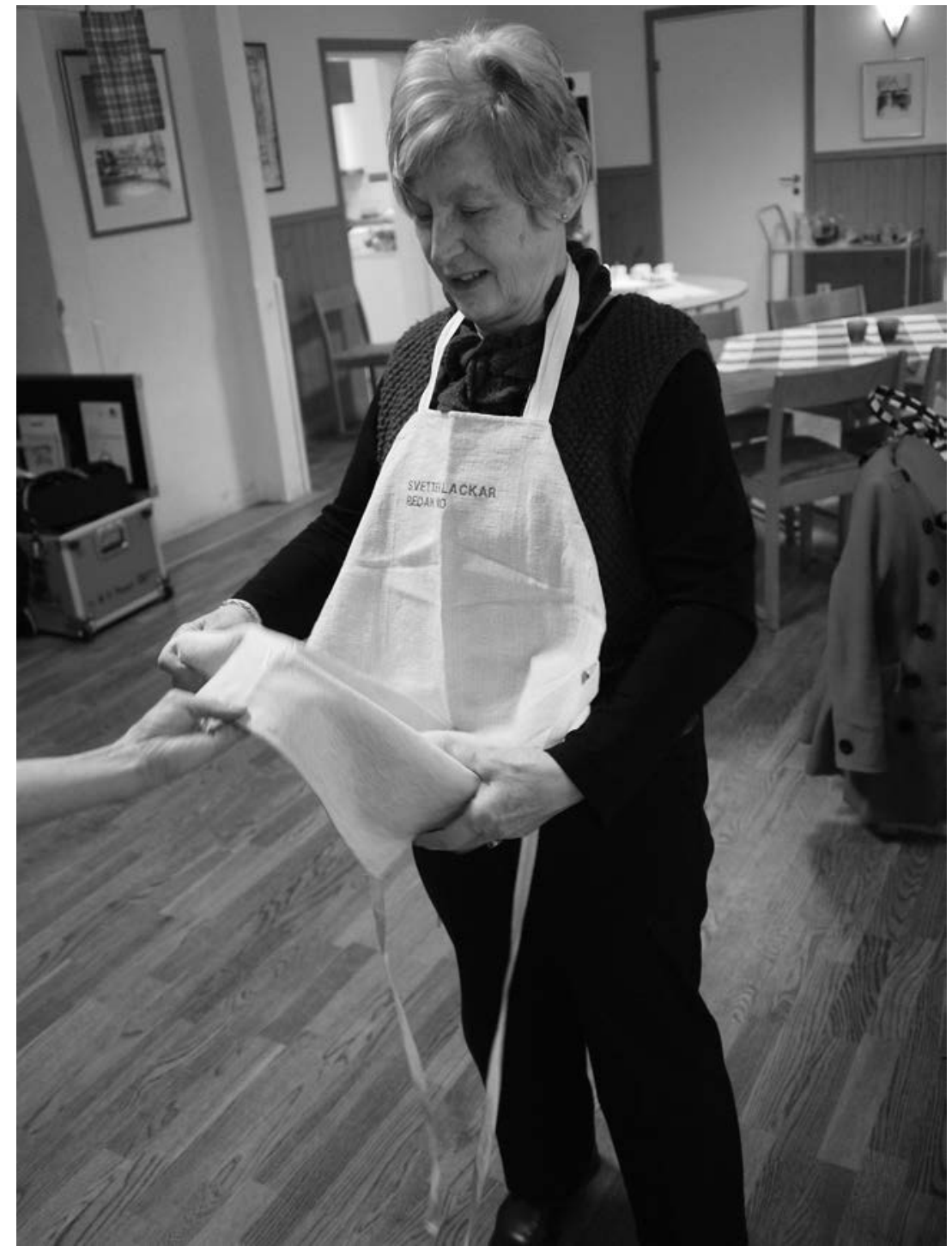

Figure $\mathbf{1 5 . 5}$

Making an apron. Kristina Lindström (CC:BY-NC). 
invitation to embroider a message received by means of SMS, but made something she found meaningful out of what she had at hand. Connections between past materials and ways of making and possible futures were made. Her concerns with the less known were, however, not settled.

During another sewing circle that was held in Stockholm, the capital of Sweden, several of the participants, who live elsewhere in Sweden, expressed how they experienced the capital as stressful. They exemplified with how people in the subway had been rushing and not looking at each other. The topic kept coming back throughout the time we spent together. A participant opposed herself to that urban/rural divide. She said that it was equally stressful in the countryside. While we would not say that her comment made any radical change to the conversation, or to the way that some of the participants experience Stockholm as stressful, there were further discussions during the days that dealt with ideas and ideals of well-being as being related to slowness and handicraft. One of the younger participants, who had moved to a ski resort in the Swedish mountains, expressed that it becomes stressful to allow oneself to take time for slowness without giving up other involvements and engagements. She was referring to having time to attend a sewing circle that she and her friends had initiated in her new home-setting. To her, there is a paradox in wanting to be part of many slow and relaxing contexts because it becomes stressful attending them all. Another participant mentioned hotels for sourdough, as an example of how the ambition of caring and allowing things to take time doesn't go well together with other commitments. At a sourdough hotel it is possible to leave the dough for someone else to do the work for you. Parts of this conversation were embroidered on a page in a textile file folder, to which the participants are invited to embroider parts of conversations that take place during the sewing circles (see figure 15.6).

Again, the makings in Threads enabled co-articulation of issues of living with technologies. The concern of having time to allow for slowness was, however, not settled.

At other times, text messages became cues to connect with experiences and people, outside of the sewing circle. At one sewing circle, one couple embroidered several text messages that they had received and sent just after the tsunami in Japan in 2011. The messages had to do with their daughter, who lived west of Tokyo. The father embroidered one message he had received, which said that the daughter would try to get to the Swedish embassy to pick up iodine, so her mother and father could wait a bit before sending iodine to her. The mother embroidered a conversation between the father and a friend of the daughter. The friend was not satisfied with the father's short replies, which resulted in the father calling the friend. This unsatisfactory SMS dialogue, in combination with the fact that they knew that the daughter was OK, became part of a discussion about the qualities-possibilities and drawbacks_of text messaging. Yet another message in the SMS-conversation between the friend and the parents was 


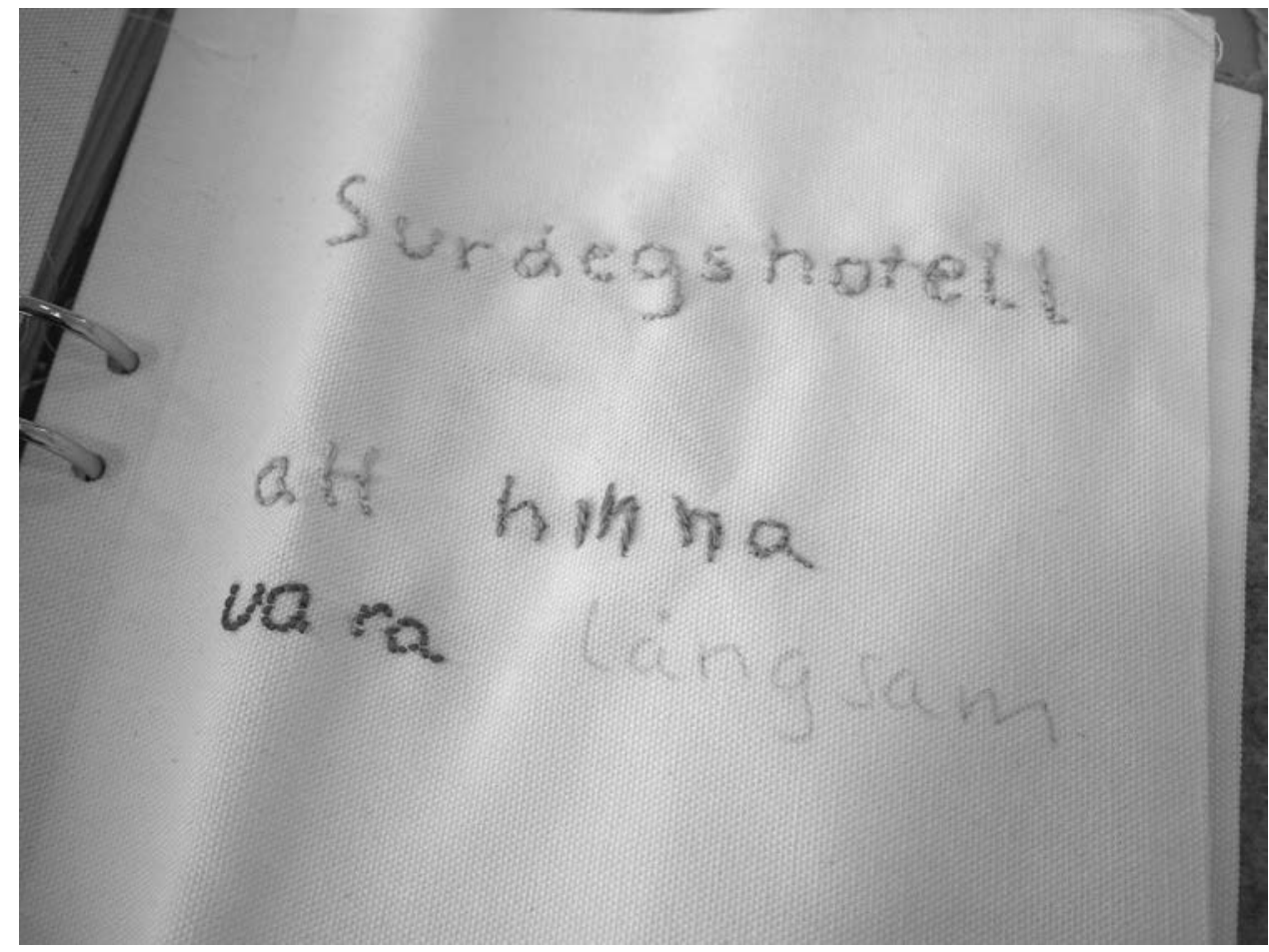

Figure 15.6

"Sourdough hotel to have time to be slow." Authors' translation to English of an embroidered message in a textile file folder. Kristina Lindström (CC:BY-NC).

embroidered by the machine on a pillow case: "OK, but nuclear power seems insecure" (authors' translation).

The ambiguity in the machine-embroidered message could have been the cue for us to talk about the more elusive presence of electricity and energy sources, and make an explicit link between the use of electricity for the embroidery machine and the fact that energy has to be produced somewhere at that very moment, but we did not. Experiences of living far apart and feelings of being (dis)connected were shared and articulated through the process of making. Possible connections between our own use of electricity and the emergency that took place in Japan, were, however, not made. This doesn't come as a surprise since the concern about a daughter easily elicits strong feelings and is less politically charged than that about nuclear power and electricity supply.

Through everyday use of technologies, we become materially implicated in a variety of potential issues. As we have shown, some of these issues are co-articulated in the 
ongoing making in Threads. The co-articulations are not coherent or fixed, but are in themselves contradictory and ambiguous. Neither are they representations of issues that were already there to be represented, but in-the-making, and articulated between multiple actors, humans and nonhumans: how we have framed the invitation with embroidering an SMS as well as what we have brought in the blue boxes and what the participants bring.

It is also important to note that these co-articulations do not offer solutions to problems. However, the co-articulations do, at times, become interventions in, or reorderings of, the participants' everyday entanglements. For example, the apron is not only part of an articulation of something, but also a reordering of sociomaterial entanglements.

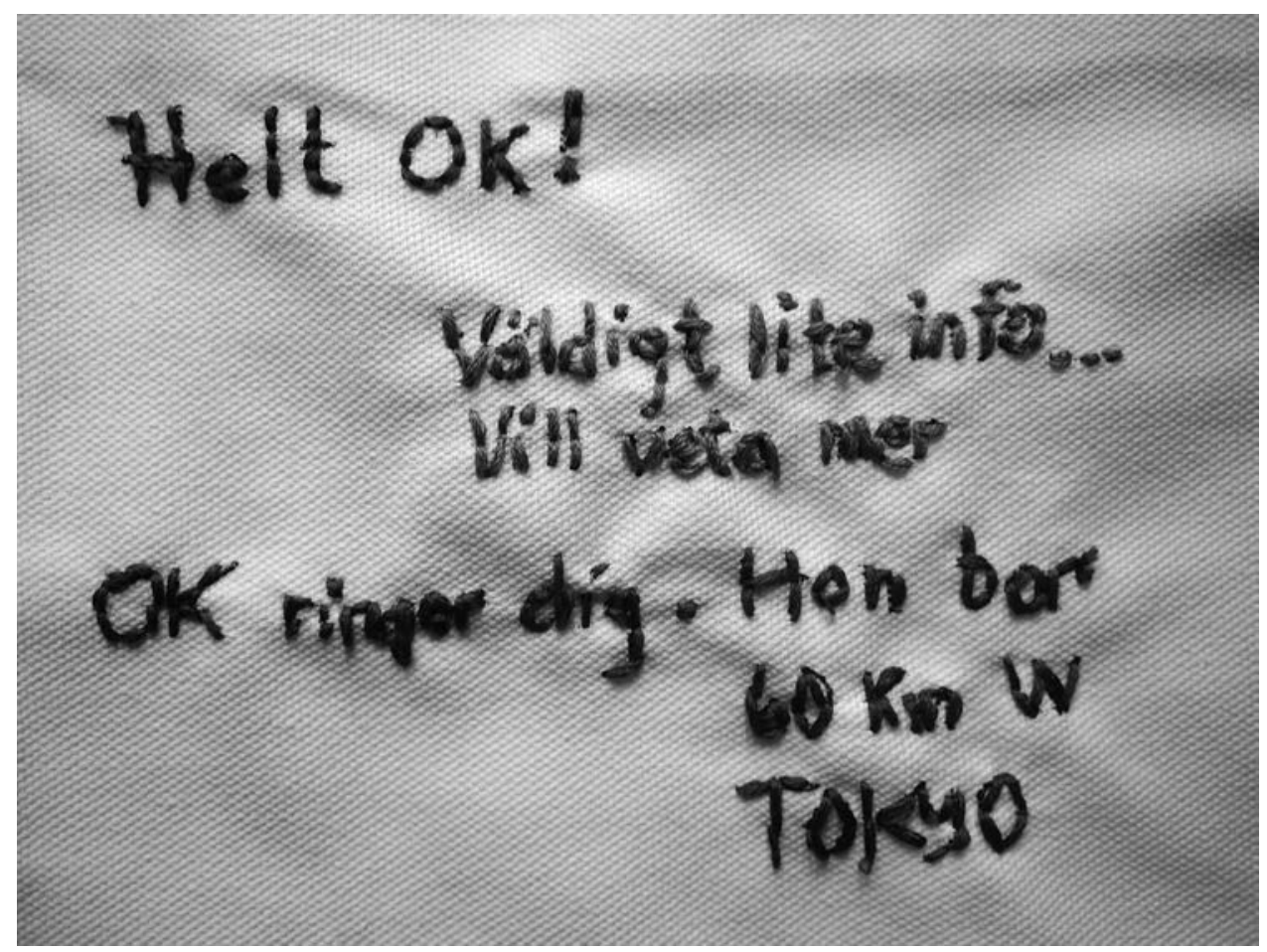

\section{Figure $\mathbf{1 5 . 7}$}

The embroidered representation of an SMS conversation between parents and a friend of a person in Japan just after the 2011 nuclear power plant accident in Fukushima. Authors' translation from Swedish: "Quite OK!," "Very little info. ... Want to know more," "OK calling you. She lives 60 km W Tokyo." Kristina Lindström (CC:BY-NC). 
This reasoning leads us over to the next section, which deals with the fact that the making that goes on in Threads is not only an intervention into the participants everyday entanglements; it also makes us entangled with making and work done elsewhere. As we will show, some of these entanglements are rarely included in the coarticulations of issues of living with technologies.

\section{Absent Present Entanglements in-the-Making}

In the last section we showed how one of the participant's making in Threads was interlinked with making done outside of Threads: the weaving of a linen cloth, which later on had been made into an apron. She could bring this making and work into presence since she was the one who had done the making. But, there is, of course, lots of other making done elsewhere that Threads as a collective is materially entangled with, although it is never articulated or in any other way brought into presence. We do, for example, not hear much about the making of the tablecloths that we set the table with. This work has so far remained absent present (Law and Singleton 2005) in Threads. By absent present we mean absent from conversations and shared experiences, but present through material entanglements. When looking at the tablecloths they have a tag saying "made by HEMTEX." Hemtex is the brand, so the tag highlights the company but obscures how, by whom, and under what circumstances the tablecloth was made.

The making in Threads has encouraged the participants to share experiences and articulate concerns, for example, related to unfamiliar technologies, stressing about having time for slowness, and living far away from loved ones. However, none of the participants have experiences of working at the assembly lines where the tablecloth, the mobile phones, or the embroidery machine have been produced. The woman's experience of weaving her linen cloth was made in a time and space which perhaps can make it possible to recognize that there is always hard labor involved in producing such a material, but it is not mirroring the conditions under which a linen cloth is produced today in other parts of the world. Nor does the HEMTEX tag help out very much.

Through our invitation, materials, and more, we do not manage to establish relations of relevance between these entanglements. Challenges with publics-in-the-making are thus that it relies on the experiences of its participants and that the materials seem to have little capacity to make certain stories present.

\section{Concluding Discussion}

In this chapter we have proposed publics-in-the-making as a specific mode of public engagement in issues of living with technologies (see also Lindström and Ståhl 2014). In short, publics-in-the-making refers to publics that come out of making things together, 
and that are continuously reconfigured by their participants-humans and nonhumans. In other words, what the issues are, are not pregiven but are in-the-making.

Other kinds of public-engagement projects could be when experts invite the public to be informed about the latest scientific and technological developments. This is an enactment of one-way communication, where experts are the knowledgeable ones. In other cases it can be that scientists or experts make some kind of audience studies or gather the publics' opinions in order to make use of them in their further development of science and technologies (see, for example, Mohr 2011; Bogner 2012).

Participatory design is an academic field that challenges the distinction between experts and laypeople. Participatory design has a long tradition of engaging the public in the design of new things and services. While some of the early participatory design projects took place mostly in workplaces, participatory design is today practiced in a range of contexts such as city planning, creative industry, and social innovation, which are also explored in this volume. Participatory design can be described as an attempt to democratize science and technology, since the aim is that those who are to be affected in the future should have a say in the decision-making process, which is recognizing that those who are affected have knowledge to contribute with (see, for example, Kensing and Greenbaum 2012). This reasoning can seem rather similar to liberal theory, in that it more or less assumes that what the issue is and who will be affected can be known in advance. In practice, we would, however, say that much work done in participatory design is about articulating issues, not as something given, but as something in-the-making, through prototypes (Ehn and Kyng 1991; Suchman et al. 2002), workshops, briefs, protocols and more. Similar reasoning can be found in Björgvinsson et al. 2012 and in Le Dantec and DiSalvo 2013, where participatory design is practiced as means of engaging publics, rather than an a priori community. This is, for example, done through infrastructuring, which suggests an ongoing engagement.

Through our proposal for publics-in-the-making we partly build on the democratic ambition of participatory design to engage publics in issues of how to live with technologies. In this chapter we have set out to explore potentialities of such an engagement, partly in terms of its potential to gather, and partly in terms of its potential as a mode of engagement. In practice, this is done through Threads.

As we have shown, Threads manages to gather despite the fact that the participants do not know each other from before, as in the case of a sewing circle, and despite the fact that the participants are not implicated in the same issue, as would be the case in publics as put forward by Dewey and Lippmann. The invitation to embroider a message received by means of SMS by hand or with an embroidery machine connected to a mobile phone with bespoke software is not a definition of a problem, but, as written earlier, an articulation of an area of curiosity, which we would frame as curiosity concerning ways of living with technologies. Since Threads has been attracting participants 
since 2009, with predecessors since 2006, we can claim that this invitation has managed to also create curiosity among its participants.

The invitation is, however, not only a way to make people gather, but it also suggests a way of engaging with the area of curiosity: through making.

More specifically, our invitation to embroider a message received by means of SMS is, as we see it, an invitation to engage with everyday entanglements. As we have shown, these engagements do at times result in co-articulations of issues of living with technologies. For example, through embroidering the specific words "Svetten lackar redan" on the specific linen cloth turned into an apron, there was a co-articulation between the woman, the materials, and the infrastructures about how to handle known and unknown issues of living with technologies. This co-articulation between various actors, including nonhumans, was an attempt at caring for familiar and less familiar entanglements as well as handling curiosity and anxiety in the same move.

When we say that this is a co-articulation rather than a representation we mean that the articulation is in-the-making. It was not simply there before to be represented, but was articulated during the making. Those that participated in the articulation were a woman, her textiles, the absence of an SMS, lack of reception and more. Furthermore, it is worth noting that these articulations are rarely solutions to a problem. And rarely do these co-articulations result in any kind of collective action to make change. This could easily be used to criticize the potentialities of Threads or, in more general terms, publicsin-the-making. In line with Marres, we would, however, argue that the problem of the public, the position of being both entangled in issues and not having access to institutions, forums, or other contexts where the matter is addressed, is also what makes the public come into being. Instead of expecting a public to offer solutions, we align with Marres, who argues that "the composition of the public-which entities and relations it is made up of-must be understood as partly the outcome of, and as something that is at stake in, the process of issue articulation" (Marres 2012, 53).

The composition of Threads is made through our invitation, as well as the multiple co-articulations that are in-the-making in Threads. Depending on what is included in these co-articulations, different stakes and stakeholders emerge.

In line with Sennett, Gauntlett, and Ratto, we can here see that thinking and making is closely entangled. Rather than treating making as something that should be separated from the public, we suggest that making can be a mode of engaging with possible issues, before they become pressing (see, for example, Perng et al. 2012) in the midst of an emergency. This should be understood as a caring approach, which doesn't come as after-the-fact ethics. Care, notably, requires ongoing engagement, which is not to be expected to be finished or solved (see, for example, Mol 2008; Mol et al. 2010; Puig de la Bellacasa 2011, 2012).

We take the co-articulations that are made in Threads to be articulations of issues of living with technologies. For example, how to handle the difficulties of a stressful 
life, whether it is in a rural or urban area, by trying to enact the promise of a slow and relaxing life by joining a sewing circle, or taking care of a sourdough. But then realizing that one has engaged in too many relaxing situations and too much slow cooking, and responding by insomnia and paying for somebody else to take care of one's sourdough at a bespoke hotel (which actually can be done in Stockholm).

What characterizes these co-articulations are that they most of all deal with issues that are of relevance in the participants' everyday lives. While we claim that the articulations are not representations of issues that were already there in advance, the participants' previous experiences of living with technologies are important parts of these co-articulations.

While one of the potentialities of publics-in-the-making is to relate to the participants' everyday entanglements, there is also a risk with this way of creating relevance through the mundane experiences of living with technologies, since more distant entanglements and distant effects of living with technologies are rarely made present or included in these co-articulations. Much like these more distant entanglements often remain absent in the participants' everyday lives, they also tend to be excluded from the co-articulations in Threads.

For example, who makes the tablecloth, the embroidery machine, and the mobile phones, out of which materials and under what circumstances, are not included in the articulations. These seem to require more care and perhaps it is a skill that could be practiced in the publics-in-the-making. But we also recognize that there is little potential in the publics-in-the-making to ask ethical questions in-the-making, when the making partly goes on at a distance from the gathering.

The co-articulations enacted in and through Threads show us that publics-in-themaking can contribute to establishing relations of relevance, but can also fail, depending on how caring curiosity is practiced in relation to the material entanglements that are brought into the present. What entanglements are brought into the present, or made part of co-articulations, matters. It matters since they are articulations of whose future and what consequences of living with technologies are cared for.

\section{Notes}

1. http://www.nordiskamuseet.se/artiklar/rekreation-och-revolution

2. http://www.kulturradet.se/Documents/publikationer/2012/kulturinstitutionerna_civila_ samhallet.pdf

\section{References}

Björgvinsson, Erling, Pelle Ehn, and Per-Anders Hillgren. 2012. Design Things and Design Thinking: Contemporary Participatory Design Challenges. Design Issues 28: 101-116. 
Bogner, Alexander. 2012. The Paradox of Participation Experiments. Science, Technology \& Human Values 37: 506-527.

Christensen, Hilda Rømer, and Bettina Hauge. 2012. Feminist Materialisms. Kvinder, Kön \& Forskning 21: 3-10.

Ehn, Pelle, and Morten Kyng. 1991. Cardboard Computers: Mocking-It-Up or Hands-on the Future. In Design at Work: Cooperative Design of Computer Systems, ed. J. Greenbaum and M. Kyng. Erlbaum.

Gauntlett, David. 2011. Making Is Connecting: The Social Meaning of Creativity, from DIY and Knitting to YouTube and Web 2.0. Polity.

Hird, Myra J., and Celia Roberts. 2011. Feminism Theorises the Nonhuman. Feminist Theory 12: 109-117.

Kensing, Finn, and Joan Greenbaum. 2012. Heritage: Having a Say. In Routledge International Handbook of Participatory Design, ed. J. Simonsen and T. Robertsson. Routledge.

Keshavarz, Mahmoud, and Ramia Mazé. 2013. Design and Dissensus: Framing and Staging Participation in Design Research. Design Philosophy Papers 1.

Law, John, and Vicky Singleton. 2005. Object Lessons. Organization 2 (3): 331-355.

Le Dantec, Chris, and Carl DiSalvo. 2013. Infrastructuring and the Formation of Publics in Participatory Design. Social Studies of Science 42: 241-264.

Lindström, Kristina, and Åsa Ståhl. 2014. Patchworking Publics-in-the-Making: Design, Media and Public Engagement. PhD dissertation, Malmö University.

Marres, Noortje. 2005. Issues Spark a Public into Being: A Key but Often Forgotten Point of the Lippmann-Dewey Debate. In Making Things Public: Atmospheres of Democracy, ed. B. Latour and P. Weibel. MIT Press.

Marres, Noortje. 2012. Material Participation: Technology, the Environment and Everyday Publics. Palgrave Macmillan.

Mohr, Alison. 2011. Publics in the Making: Mediating Different Methods of Engagement and the Publics These Construct. Science and Engineering Ethics 17: 667-672.

Mol, Annemarie. 2008. The Logic of Care: Health and the Problem of Patient Choice. Routledge.

Mol, Annemarie, Ingunn Moser, and Jeanette Pols. 2010. Care in Practice. On Tinkering in Clinics, Homes and Farms. Transaction.

Perng, Sung-Yueh, Monika Büscher, Lisa Wood, Ragnhild Halvorsrud, Michael Stiso, Leonardo Ramirez, and Amro Al-Akkad. 2012. Peripheral response: Microblogging during the 22/7/2011 Norway attacks. In Proceedings of Ninth International ISCRAM Conference, Vancouver.

Puig de la Bellacasa, Maria. 2011. Matters of Care in Technoscience: Assembling Neglected Things. Social Studies of Science 41 (1): 85-106. 
Puig de la Bellacasa, Maria. 2012. "Nothing Comes without Its World": Thinking with Care. Sociological Review 60: 197-216.

Ratto, Matt. 2011a. Critical Making: Conceptual and Material Studies in Technology and Social Life. Information Society 27: 252-260.

Ratto, Matt. 2011b. Open Design and Critical Making. In Open Design Now: Why Design Cannot Remain Exclusive, ed. B. van Abel, R. Klaassen, L. Evers, and P. Troxler. BIS.

Sennett, Richard. 2008. The Craftsman. Yale University Press.

Suchman, Lucy, Randall Trigg, and Jeanette Blomberg. 2002. Working Artefacts: Ethnomethods of the Prototype. British Journal of Sociology 53 (2): 163-179.

Waldén, Louise. 2002. Textilens text. In Tyg överallt. Nordiska museets och Skansens årsbok.

Åsberg, Cecilia, and Nina Lykke. 2010. Feminist Technoscience Studies. European Journal of Women's Studies 17: 299-305. 